\title{
Automated Allocation of Resources for Examination System using Genetic Algorithm
}

\author{
Loganathan R, Smitha Kurian
}

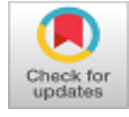

\begin{abstract}
The quality of education is to a major extent assessed through examination and therefore examination is an inseparable and integral part of education. Even though we have seen a lot of technological advancements, the examination process is still carried out the traditional way with most of the process performed manually. As a result of which the current system at times are prone to errors and are time consuming. Various techniques have been proposed to automate the time table generation, automatic paper setting and evaluation. One of the tasks that has not got much attention is the assignment of work on a per day basis to invigilators and their assignment to rooms for invigilation. So we propose a system that integrates task like invigilator allotment, room allotment student allotment and time table generation in an efficient way.
\end{abstract}

Keywords: Resource allocation, Invigilator allocation, Application of Genetic algorithm, automation

\section{INTRODUCTION}

One of the components of the education system is the examination. The education system is incomplete without assessment which measures the outcome of the education. The institutions running various programs have various courses and each student has to be evaluated for all the courses undertaken. The evaluation process is periodical and so should be repeated during the tenure of the course.

The examination process will start with the generation of time table which fixes the day and slot of conducting the exams. In parallel a process should be in place which sets question papers for effective evaluation of various courses. In most of the universities the question paper setting and the score maintenance is centrally managed by the universities. The burdens on the individual independent institutions are the allocation of two main resources that is allocation of class room for the students and allocation of invigilators for each class room.

Once the students are allotted to the rooms, the number of rooms required for the exams can be known. The exam to be conducted in a room is also decided by the students and the

Revised Manuscript Received on December 30, 2019.

* Correspondence Author

Dr. Loganathan R, Department of Computer Science and Engineering, HKBK college of Engineering, affiliated to VTU, Bengaluru, Karnataka, India. Email: drloganathanr@gmail.com

Smitha Kuriab Department of Computer Science and Engineering, HKBK college of Engineering, affiliated to VTU, Bengaluru, Karnataka,

(C) The Authors. Published by Blue Eyes Intelligence Engineering and Sciences Publication (BEIESP). This is an open access article under the CC BY-NC-ND license (http://creativecommons.org/licenses/by-nc-nd/4.0/) India. Email: smitha.nikku@gmail.com

course that is taken up by the student. So the allocation of students to room is a challenging task should be efficiently done considering various constraints.

Once the students are allotted then the next challenging task is the allocation of invigilators to each room. It is a resource allocation problem under constraints which is also a combinatorial problem.

We propose to build a web based system that is securely accessible by the students, head of the institutions and faculties who are the invigilators of the exam. Based on the type of users the system has to make sure that the data access is controlled and only the relevant information is available by each user.

If a brute force technique is followed to solve the problem the solution is static, does not take care of the constraints, time consuming and wastes a lot of resources

The main objective is to enable the institutions to conduct examinations efficiently by decreasing the resource allocation time and by making the resources optimally.

The paper is organized with section 2 describing the Literature survey, section 3 describes the proposed system section 4 describes the implementation and result and section 5 concludes the paper specifying the future scope.

\section{LITERATURE SURVEY}

The system includes management of the users, automatic question paper generation, assigning scores to test paper sand also takes care of giving feedback to students[1].

Room allocation during examination can be automated using genetic algorithm. This system also managed questions and conduction of test online [3].

The authors have Proposed a method for scheduling the exam time table using genetic algorithm [4].The authors here have realized the user login, security authentication, question bank management, test paper management, online examination, announcement, sourcing, check results etc.[5].

This paper also describes the automatic generation of test paper algorithm, and discusses the security of the system6].

The authors have proposed an asynchronous e-learning system which automates the process of question paper setting, live monitoring of test and documentation of result [7]. A tabu based search approach is proposed for efficient and scheduling of $r$ resources in a radiological examination process. Here the system could improve the patient throughput and efficiently utilize the radiological resources [8]. Here the various tasks of examination system that are manually performed such as time table generation, searing allotment, invigilator allotment are automated. But during invigilator allotment the moderator selects the dates and rooms the faculties are allotted [9]. 
The authors have propose to automate the exam cell activity where the students will not have to queue up to fill the various forms and follow the procedures to gain access to hall tickets and various exam notices [10].

Existing systems have employed various techniques to propose system that automates the process of time table efficient approach is also proposed using genetic algorithm and graph coloring to allocate exams to rooms and students to rooms. Allocation of invigilators to rooms is a process that has not received much attention. Optimal allocations of invigilators are highly constrained and time consuming. We propose a technique in the next section for the invigilator allocation.

\section{PROPOSED SYSTEM}

For large universities conducting courses at various levels the examinations are scheduled for a period of 15 to 30 days. On every day the exam is scheduled, after the students and exams are allotted to rooms, every room has to be assigned with at least one invigilator this process has to be repeated for every day the exam is conducted.

A.Problem statement: We propose a system that integrates user management, room allotment to students and invigilator allotment in a dynamic and efficient way considering the various constraints. It also differentiates the users with permission to view and edit.

The system specifies three types of users they are student, faculty who are invigilators and the admin who is the controller of exams.

The administrator is the head of the institution and is responsible for user management, Resource (Room/Invigilators) allocation and Time table generation. The students are only allowed to view the room allotment on the day of the exam and can also view the time table.

Faculties only have permissions to view the list of days on which they have to perform invigilation. The specific room for invigilation is allotted only on the day of the exam dynamically. The system overview is specified in Figure 1.

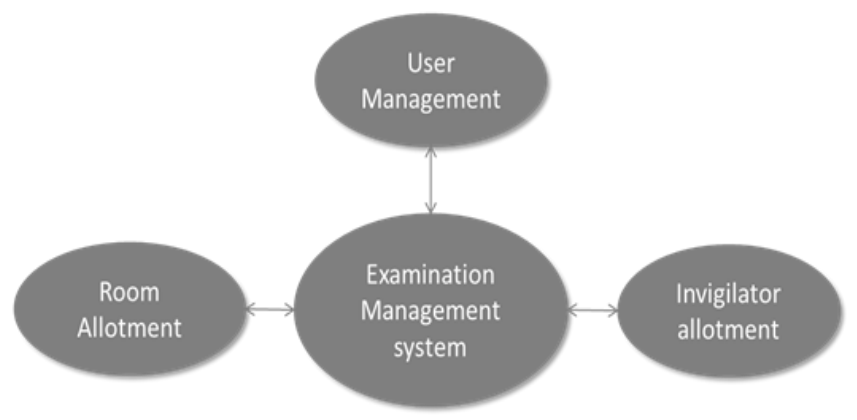

Figure 1. System Overview

\section{B. Student room allotment constraints}

1. Student should be allocated to rooms dynamically.

2. Student will be aware of the room allotment only on the days of the exam.

3. Number of students allotted to room should be less than or equal to the capacity of the class room.

4. If a desk has a seating capacity $>2$ then the student allotted should belong to at least two different courses and the number of students allotted to room should be less than or equal to twice the capacity of the class room. generation, question paper setting and score management. An

\section{Invigilator allotment Constraints}

1. Faculty will invigilate the exam of the course that the faculty has not handled.

2. Each faculty should be allocated with the same number of invigilation duties

3. Efficiently allocate resources so that each faculty will be assigned with minimum number of duties.

4. There should be back up invigilators to take care of absenteeism

5. Invigilator allotment should be dynamic.

a. Faculties should be aware of the day of invigilation well in advance.

b. Faculties will be aware of the room allotted for invigilation only on the day of the exams.

c. Each room allotment should be dynamic (changes every day and is unpredictable).

d. Faculties will not be assigned duties on consecutive sessions.

\section{Time table generation}

If the date and time of the exam is selected courses will be selected from the database and time table will be automatically generated. A sample layout is represented in Table 1.Where the Program (P), Semester(S) and course(C) is indicated. The number of days (nod) for which the exam is scheduled depends on the number of courses in the program

Table 1: Layout of time table

\begin{tabular}{|c|c|c|}
\hline Dates & Session-1 & Session-2 \\
\hline Day-1 & $\begin{array}{l}\text { P1-S1-c1 } \\
\text { P2-S1-c1 } \\
\text {.. } \\
\text { P6-S1-C1 }\end{array}$ & $\begin{array}{l}\text { P1- S5-C1 } \\
\text { P2- S5-C1 } \\
\text {. } \\
\text { P6- S5-C1 }\end{array}$ \\
\hline Day-2 & & \\
\hline Day-3 & & \\
\hline Day-nod & $\begin{array}{l}\text { P6- S4-C6 } \\
\text { P2- S4-C6 } \\
\text {.. } \\
\text { P6- S4-C6 }\end{array}$ & $\begin{array}{l}\text { P6- S8-C6 } \\
\text { P2- S8-C6 } \\
\text {. } \\
\text { P6- S8-C6 }\end{array}$ \\
\hline
\end{tabular}

The main constraint her is that if a student is allowed to take the exam for more than one course then those exams should not be scheduled on the same day. As an assumption a student of higher semester is allowed to take up the exam for the courses of current academic year (CAY) and (CAY-1) if they have a backlog course which the student could not qualify in the previous attempts.

\section{E. Room allotment for internal exams}

\section{Assumptions:}

Every day in each session exams are conducted for one course of each program. Each seat has capacity 1.

Therefore Number of students (n) allotted to room should be less than or equal to the capacity $(\mathrm{C})$ of the class room. All the class rooms have the same capacity. Each student (stud_id), department(dept_id) and room(room_id) is identified with a unique identifier. Total number of rooms(r) available is known. Total number of students attempting a course is also known 


\section{Algorithm for room Allocation}

Repeat

$P 1=\operatorname{random}(1 . .6)$

Until(p1not previously selected)

$n=\operatorname{random}(1 . . r) \quad / /$ if room not full

assign students from $p 1$

if students remain

$n=(n+1) \% r / /$ select next room

else

\section{repeat process with next two programs}

\section{F. Invigilator allotment}

Once the students are allotted to rooms, number of rooms required per day (NR) and the number of invigilator (NI) requirement per day is also known. We assume that the total number of faculty $(\mathrm{N})$ in the institute is also known. With these data we will be able compute the total number of invigilators (TNI) required for the exam and the number of invigilation duty (NID) to be assigned to each invigilator can be computed.

$$
T N I=\sum_{1}^{\operatorname{nod}} N I+2 * \text { nod }
$$

Two times nod takes care of absenteeism.

$$
N I D=\frac{T N I}{N}
$$

Now the challenge is to assign the days on which the invigilators have to carry out the invigilation duty. Now the resource allocation (invigilator) has to be done that it should not exceed NID value for each invigilator. Each day should have the required NI and also satisfies the invigilator constraints 2 to 5 .

The genetic algorithm is applied to find an optimal invigilation duty allotment. Genetic algorithm is based on the biological mechanism of natural selection where in a competing environment the fittest individual survive. The solution is assumed to be an individual member and can be represented as a set of parameters called genes. A fitness value is used to select the best individual [11].The pseudo code of the genetic algorithm is given in fig below.

START
Generate the initial population
Compute fitness
REPEAT
$\quad$ Selection
Crossover
Mutation
Compute fitness
UNTIL population has converged
STOP

Figure 2 Pseudo code of Genetic algorithm[12]

The algorithm for the invigilator duty allotment which is based on genetic algorithm is given below. Here a two dimensional array of $\mathrm{N} \mathrm{X}$ nod is considered as an individual member

\section{Algorithm for Invigilator duty allotment \\ Compute optimal fitness value (OFV) \\ Generate individual (1- slot allotted, 0 - slot not allotted)}
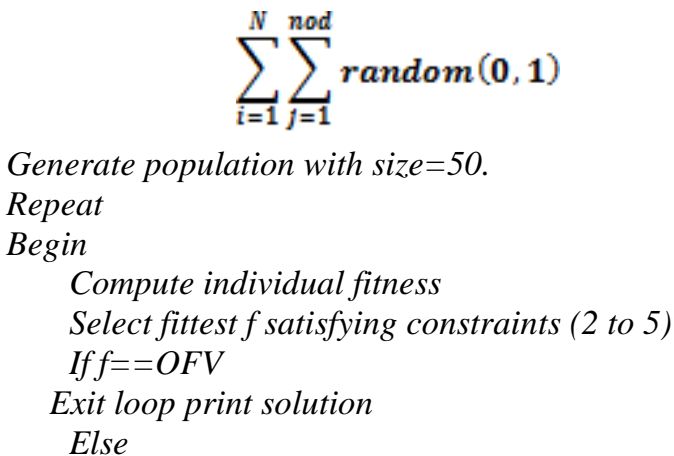

Evolve population by crossover and Mutation

End

\section{IMPLEMENTATION AND RESULTS}

A Java based application is built to implement the proposed system. For the implementation purpose we have considered the case study of undergraduate program that requires four years to complete. Each year consist of two semesters. The institute has 6 programs and each program consist of 6 courses every semester. During every semester three internal tests are conducted at the institute level and one exam conducted at the university level. All the modules in the proposed system is implemented and integrated into a desktop application

\section{A. User management}

MySQL database was used to maintain the database which stores the information of the faculty, students, room, departments, and courses. A user friendly web based GUI was also developed. Different types of login were created with different access permissions.

\section{B. Results}

After 250 generations the algorithm produced a near optimal allocation. Every row of the fittest individual will indicate the days on which each individual invigilator is assigned invigilation. Every column indicates the list of invigilators for a particular day.

On every day of the exam every invigilator who has duty on a particular day is randomly assigned to one of the exam rooms provided it satisfies the invigilator constraint 1.

The table 2 a sample of the invigilator allocation

Table 2. Invigilator allocation

\begin{tabular}{|l|l|l|l|}
\hline S\# & Room No. & Invigilator Name & Session \\
\hline $\mathbf{1}$ & A101 & ABC & 1 \\
\hline $\mathbf{2}$ & A102 & XYZ & 1 \\
\hline 3 & A103 & PQR & 1 \\
\hline$\cdot$ & & & \\
$\cdot$ & & & \\
$\cdot$ & & & \\
\hline
\end{tabular}

\section{CONCLUSION}

The paper proposes a technique to automate the process of the conduction of exam. The two important resources that need to be allocated during the exams were the rooms where the exams are conducted for the students and invigilators for each room where the examination is being conducted. 
These allocations were made considering the various constraints involved. The paper proposed a technique of random allocation to obtain a dynamic room allotment. It employs the genetic algorithm to obtain an efficient invigilator allotment. The genetic algorithm that was based on natural selection provided a near optimal solution for the resource allocation. The paper can be further enhanced to model it as a mobile app which includes notification for students and invigilators during exam.

\section{REFERENCES}

1. Huiqiang $\mathrm{Lu}$, Ying $\mathrm{Hu}$ The Design and Implementation of Online Examination System Based on J2EE, page International conference on Industrial Control and Electronics Engineering (ICICEE), pages 93-95 (C) 2012 IEEE

2. Sandeep Saharan \&KarunaKadianA multi-objective genetic room allocation in examination scheduling using graph coloring, International Conference on Signal Propagation and Computer Technology (ICSPCT),pages 514-518,@2014 IEEE

3. Indu Sharma, Anjali Singhal, Research on Online Examination System, International Journal of Engineering Technology, Management and Applied Sciences, Volume 2 Issue 3, August 2014

4. Manoj Kr. Mahto1 , Mr. Lokesh Kumar2 ,Exam Time Table Scheduling using Genetic Algorithm, International Journal of Enhanced Research in Management \& Computer Applications, Vol. 4 Issue 8, August-2015

5. Zhang Yong-sheng,, Feng Xiu-mei1, , Bao Ai-qin,The research and Design of online examination system, $7^{\text {th }}$ International conference on Information Technology in Medicine and Education, pages 687-691 (C) 2015 IEEE

6. DeepankarVishwas Kotwal1, ShubhamRajendra Bhadke2, Aishwarya Sanjay Gunjal3, Puspendu Biswas4,ONLINE EXAMINATION SYSTEM, International Research Journal of Engineering and Technology (IRJET), Volume: 03 Issue: 01 ,Jan-2016.

7. Catherine Vafeiadou, PantelisVasiloudis, Minas DasygenisOnline automatic examination system for digital circuits, $5^{\text {th }}$ international conference on Modern circuits and system technologies, June 2016

8. Chun-hua HE, Tabu search based resource allocation in radiological examination process execution, Frontiers of Information Technology \& Electronic Engineering, volume 19, issue 3,march 2018.

9. Vamsi Krishna Yepuri, Gopi Chand Pamu, Naveen Kodali , Pradyumna L V,Examination Management Automation System, International Research Journal of Engineering and Technology (IRJET), April 2018

10. Rakshit Patki1, Saranya Nair, Indira joshi, International Research Journal of Engineering and Technology (IRJET), Volume: 06 Issue: 03 , Mar 2019.

11. K. F. Man,K. S. Tang, S. Kwong, ,Genetic Algorithms: Concepts and Applications, IEEE TRANSACTIONS ON INDUSTRIAL ELECTRONICS, VOL. 43, NO. 5, OCTOBER 1996

12. https://towardsdatascience.com/introduction-to-genetic-algorithms-inc luding-example-code-e396e98d8bf3

\section{AUTHORS PROFILE}

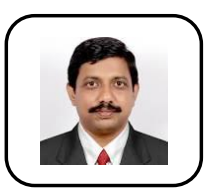

Dr. Loganathan R. Received B.E in CSE from Bharathiar University, Coimbatore, M.TECH IN CSE from Visvesvaraya Technological University, Karnataka. PhD in CSE from Sathyabama University, Chennai. He is now working as Professor and HOD CSE of HKBK College of Engineering, Bangalore. He has 20 years of Academic experience. He published his research work in several reputed journals and conferences in the field of Image Processing, Wireless Networks.

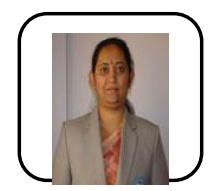

Smitha Kurian:Received B.E. in CSE from SJMIT, Kuvempu University, M.Tech from VTU and is a Research Scholar at VTU. Currently working as Assistant Professor, Department of CSE HKBKCE. Published various journal in conferences and journals in the field of

Machine Learning Wirelss AdHoc networks, Artificial Intelligence and 